\title{
Medicinal uses and health benefits of chili pepper (Capsicum spp.): a review
}

\begin{abstract}
Pepper have been grown and used in Eritrea for long period of time and is part of the Eritrean food culture. Eritrean pepper germplasm was found to be highly diversified that can serve different uses and purposes. Globally pepper is known for its high nutritional value, health benefits and medicinal properties. It is reach (Rich) in vitamins and minerals, has antimicrobial and anticancer properties. Chili pepper has preventive and therapeutic properties for many ailments such as different types of cancer, rheumatism, stiff joints, bronchitis and chest colds with cough and headache, arthritis, heart arrhythmias and many other ailments. Despite traditional medicine including medicinal plants is widely practiced in Eritrea, there is no evidence that pepper was used as medicinal plant. Thus the purpose of this review was to spotlight on the medicinal uses and health benefits of this well-known and widely consumed plant for encouraging research works to address issues related to safety, efficacy, quality, and development and avoid potential risks, especially those linked to aflatoxin contamination.
\end{abstract}

Keywords: chili pepper, capsaicin, medicinal use, health risks, aflatoxin
Volume 6 Issue 4 - 2018

\author{
Brhan Khiar Saleh, ' Abdella Omer, ${ }^{2}$ Belay \\ Teweldemedhin' \\ 'Department of Horticulture, Hamelmalo Agricultural College, \\ Eritrea \\ 2Department of Agronomy, Hamelmalo Agricultural College, \\ Eritrea
}

Correspondence: Brhan Khiar Saleh, Department of Horticulture, Hamelmalo Agricultural College, PO Box, 1286 , Asmara, Eritrea, Tel +29I-7II-7725, Email brhan200220@yahoo.co.uk

Received: May 29, 2018 | Published: July 05, 2018

\section{Introduction}

Chili peppers originated in Mexico after the Columbian Exchange, many cultivars of chili pepper spread across the world, used for both food and traditional medicine. ${ }^{1}$ Pepper (Capsicum spp.) is one of the oldest domesticated and utilized crops. Its use dates back to more than 7000 years in Mexico and is believed to have originated in tropical America. ${ }^{2,3}$

Pepper belongs to the genus Capsicum which is a member of the Solanaceae family. The genus Capsicum consists of approximately 31 species of which the five domesticated species are $C$. annuum, C. baccatum, C. chinense, C. frutescens, and C. pubescen. ${ }^{4}$ Average world production and cultivated area of dry and green peppers are estimated at 3.9 and 34.5 million tons respectively; harvested from 1.8 and 1.9 million hectares for both dry and green peppers respectively. ${ }^{5}$ Despite their vast trait differences most pepper cultivars commercially cultivated in the world belong to the species, C. annuum. However, both $C$. frutescens and $C$. chinense, are currently widely grown. ${ }^{3}$

Pepper has been grown and used in Eritrea for very long time, but the exact time when it was introduced is unknown, ${ }^{6}$ however, Andrews $^{2}$ mentioned it probably rich ed the port Masawa in 1520 . A recent molecular diversity study revealed that Eritrean pepper is highly diversified and can provide genotypes for various uses. ${ }^{7}$ No published data available for current chili pepper cultivated area and production in Eritrea, however, Saleh ${ }^{8}$ found it to be 4132 ha and 15,118 tons respectively.

Pepper is the most widely used spice and condiment in the world and is greatly priced for its pungency and adding special flavor to many cuisines throughout the world. ${ }^{2}$ Historically it was used mainly for seasoning and as medicinal plant, but today its use extended to fresh and processed vegetable, spice, dried forms, used as food dye, bred as ornamental plant and production of extracts for various pharmaceutical and cosmetics industry. ${ }^{9,10}$ In Eritrea it is an ingredient in preparation for almost all Eritrean dishes. Average weekly household consumption of dry pepper in Eritrea is estimated at 140 grams. It is consumed as powder prepared from dry pods called 'berbere' which is added to dishes as a food dye and spice. The dry red pods are also the main component for preparing 'shiro' powder, which is a popular sauce in Eritrea. The green pods are eaten raw as a salad or appetizer and cooked with various ingredients. ${ }^{6}$ Due to the local production of dry pepper is lower compared to the demand the difference is usually imported. The value of imported dry pepper in 2011 was estimated at US \$10million. Only small amount of the pepper consumed in Eritrea is produced locally and is consumed as fresh pods, while the bulk of dry pods are imported. ${ }^{6}$ Although exact figures for the current imports are not available, however, Saleh ${ }^{7}$ indicated the value of dry pepper imports for 2011 to be US \$10million.

Traditional medicine including herbal medicine is still widely practiced in most developing countries, while the use of complementary and alternative medicine is rapidly increasing in developing countries. In Eritrea the use of traditional medicine is similar to other countries with rich traditional medicinal practices in various aspects. ${ }^{11}$ Pepper is one of the most important plants that have been used as medicine for long time in different countries and civilizations. In old civilizations it was used by the Mayas for treating asthma, coughs, and sore and by the Aztecs to relieve toothaches. ${ }^{3}$ In Eritrea pepper is part of the food culture that is usually in daily consumption and generally Eritreans believe that pepper has health benefits, however, no information regarding its medicinal use. Absence of pepper in the lists of medicinal plants used in Eritrea, presented by Senai ${ }^{11}$ is an indicator for not using it as medicinal plant or at least not widely used, specially majority of the plants were collected from the highlands were pepper is part of the food culture. According to WHO questions about the safety, efficacy, quality, availability, preservation and further development of this type of health care are still in place. An evidence based report by Arthritis Research UK showed that around four out of 10 people in the UK use complementary medicine (includes herbal medicine) at some point in their lives and suggested the report may help people to select useful treatment. ${ }^{12}$ Thus the objective of this review is to spotlight on the nutritional value, health benefits and medicinal properties and uses of pepper to create awareness and encourage research works so that it is properly used and potential risks avoided. 


\section{Nutritional value}

Chili peppers are rich in many minerals, vitamins and amino acids essential for human health and growth. Pawar et al., ${ }^{13}$ found chilies to hold all the best properties to be considered as a food. Peppers contain wide array of phytochemicals such as vitamins, phenolics and flavonoids that are important anti-oxidants which may reduce degenerative diseases. ${ }^{14,15}$ Peppers are rich in vitamin $\mathrm{C}$, vitamin $\mathrm{A}$, vitamin $\mathrm{E}$ most $\mathrm{B}$ vitamins and in particular vitamin B5. ${ }^{15,16}$ They also are very high in potassium, magnesium, iron and rich in calcium and phosphorus. ${ }^{13,14}$ Peppers include many species and hundreds of varieties and types. They are consumed as fresh unripe fruits, ripened red or other colors and dried forms. The different species, varieties and consumption forms vary in their nutritional and anti-oxidant contents. ${ }^{15}$

\section{Capsaicin the active Ingredient}

Capsaicin an alkaloid in chili peppers that makes them hot, is used as an analgesic in topical ointments, nasal sprays, and dermal patches to relieve pain. ${ }^{17}$ Fruit pungency which is probably the most important flavor trait of peppers is characteristic of the genus Capsicum and it is due to an alkaloid compounds known as capsaicinoids that are unique to Capsicum., ${ }^{4,18}$ The capsaicinoids are commonly called capsaicin because it is the most prevalent among the seven capsaicinoids followed dihydrocapsaicin. The rest five compounds (norcapsaicin, nordihydrocapsaicin, nornordihydrocapsaicin, homocapsaicin and homodihydrocapsaicin), are considered minor capsaicinoids. ${ }^{3}$ Capsaicin and its related compounds are the active ingredients in pepper that are related to the anti-microbial and anti-carcinogenic and other medicinal properties in pepper. Scoville organoleptic method and High Performance Liquid Chromatography (HPLC) are used for measuring pungency. ${ }^{18,19}$ Pungency is dependent on the genetic makeup of the pepper plant and other environmental factors. ${ }^{20}$ Among the cultivated peppers C.annuum is the most variable in pungency and both C.chinense and C.frutescens are the highest and C.baccatum the lowest while C.pubescens is mild. ${ }^{18}$

Pungency in pepper is controlled by a single dominant gene located at the Punl locus of the capsicum chromosome 2. ${ }^{21,22}$ The difference between the pungent Pun1:Pun1 and the non-pungent pun1:pun1 genotypes is a large $2.5 \mathrm{~kb}$ deletion in the genomic sequence of the non-pungent genotypes, while in the pungent genotypes the deletion is absent. ${ }^{21}$ The deletion leads to change in biochemical pathway for the production of capsaicinoids..$^{22}$ Stewart et al., ${ }^{21}$ identified SB2-66 as a candidate gene for pungency which was co-located with Punl locus in chromosome 2. Similarly, Rodrýguez-Maza et al., ${ }^{18}$ designed MAP1 marker this useful for marker assisted selection.

A preliminary survey conducted in 2011 by the Department of Horticulture of Hamelmalo Agriculture College to investigate pepper consumer preference showed that majority of the respondents preferred medium level pungency and avoided extremely high levels. ${ }^{13}$ To date no data available regarding analysis of pungency of the Eritrean pepper germplasm. However, referring to the Ethiopian variety Marecofana which is widely consumed in Eritrea, the pungency preferred by the Eritrean consumer could be in the range 6,700-18,800 SHU. This range for Marekofana was reported for samples of this variety collected from different pepper growing regions of Ethiopia. ${ }^{23}$

\section{Health benefits}

\section{Reduction in mortality rate}

Wikipedia (2016) mentioned that a study published by the British
Medical Journal found some indications that humans who consume spicy foods, especially fresh chili peppers, were less likely to die of cancer or diabetes. Reported results of population based cohort study in china and showed inverse correlation between spice consumption (mainly chili pepper) and both total and cause specific mortality rate. They found consumption of spicy food 6 to 7 days cause $14 \%$ relative risk reduction in total mortality.

Since fresh and dried peppers differ in their nutritional and active ingredients content ${ }^{14}$ it is expected to have different effects. Found the inverse associations of daily spicy food consumption with death due to cancer, ischemic heart diseases, and diabetes to be stronger when fresh chili consumed compared to non- fresh chili.

\section{Therapeutic properties}

A vanilloid receptor known as VR1 which was later found to be member of the family TRP and was called TRPV1 (transient receptor potential vanilloid subtype 1) is the receptor for capsaicin and is universally distributed in the brain, sensory nerves, dorsal root ganglia, bladder, gut, and blood vessels. ${ }^{24-27}$ Capsaicin is activate and then desensitize or block VR1 and was found to be powerful drug in animal models of human disease. ${ }^{25}$ Capsaicin plays a potential role in cardiometabolic protection through the activation of TRPV1 in different target organs or tissues, which suggests that TRPV1 may be a promising target for the management of cardiometabolic diseases such as obesity, hypertension, dyslipidemia, diabetes and atherosclerosis. ${ }^{26,27}$ However, association between the dosage of dietary capsaicin and the effect on cardiometabolic protection need to be clarified for determining the daily usage or intake of capsaicin or its derivatives. ${ }^{27}$ The activation of VR1 by capsaicin make it possible to be involved in various human disease states ranging from genetic pain insensitivity to chronic pain syndromes. In addition to that VR1 has much broader clinical benefits than mere pain case. ${ }^{25}$

Chili pepper has preventive and therapeutic properties for many ailments such as different types of cancer, rheumatism, stiff joints, bronchitis and chest colds with cough and headache, arthritis, heart arrhythmias and used as stomachic. ${ }^{13}$ Chili preparations for treating ailments can be standard capsaicin, pharmaceutically prepared gels, creams and plasters, essential oils distilled from pods, powder prepared by crashing pods and extracts by soaking pods in water or ethanol. ${ }^{12-14}$

Report of the Arthritis Research UK found capsaicin effective for treating osteoarthritis and fbromyalgia compared to placebo and can be used safely. ${ }^{12}$ The ability of capsaicin to be used for treating pains and aches is due to it has the capacity of depleting nerves of their supply of subsistence $\mathrm{P}$ which is a neuropeptide responsible of sending signals of pain to the brain thereby preventing transmission of pain feeling., ${ }^{2,12}$

Pepper has antimicrobial properties that are important for human health. However, the results of experiments were variable. Abdul Salam $^{14}$ tested the antimicrobial property of pepper and found ethanol extracted pepper was more effective than aqueous extracted, but both were less effective compared to standard capsaicin. While Omolo et al., ${ }^{28}$ tested crud pepper extract and found capsaicin was less inhibitor compared to other pepper compounds and suggested various reasons may contribute in the differences between results, including inconsistency between analyzed plant materials.

Dietary antioxidants has protective role against many diseases such as cancer, diabetics, cardiovascular and anemia. Vitamins E, C and $\beta$-carotene are important as protective antioxidant and peppers are 
rich in vitamins $\mathrm{C}$ and $\mathrm{E}$ as well as carotenoids and xanthophylls. ${ }^{29,30}$ Antioxidant levels and responses in paper varies according to variety, growing stage and environmental conditions. Perucka \& Materska ${ }^{29}$ found extracts from hot peppers were higher in vitamin $\mathrm{E}$ and $\beta$-carotene, however, extracts from sweet varieties were higher in antioxidant content and phenolic compounds. Similarly, Mateos et al. ${ }^{30}$ reported fruits of the same type or cultivar responded similar in antioxidant activities in response to variable temperature levels. On the other hand ${ }^{31}$ found pepper fruits at ripe red stage were higher in antioxidant activity compared to fruits at green mature stage.

\section{Health risks of pepper}

Although most studies show that pepper and its compounds are safe, some reports indicated it may be related to some cancer risks. Hwang et al., ${ }^{32}$ reported capsaicin may be linked to skin cancer. In Bolivia, Peru and Chile, high gallbladder cancer (GBC) incidence rates were found to be related with high red chili pepper consumption. ${ }^{33,34}$ Szllasi \& Blumberg ${ }^{35}$ reviewed mutagenic effects of capsaicin on bacteria and mammals and found conflicting results. However, they concluded capsaicin is not a mutagenic or it is a weak mutagenic. Reports of experiments on animals also showed pepper consumption could have carcinogenic or cocarcinogenic effect. ${ }^{35}$ However, since these experiments used extremely high volume of pepper or concentrations of capsaicin which are extremely far above the normal human consumption, it may be difficult to be considered as risky carcinogenic for humans. In addition to that no confirmation the carcinogenic effect is due to capsaicin or other compounds in pepper. Similarly, $\mathrm{SCF}^{36}$ stated that high consumption of chilies in Mexico and India (25-200mg/day) was reported to be associated with cancer of the upper digestive tract. In contrast, the maximum daily intake from mild chilies and paprika in Europe was roughly estimated to be $1.5 \mathrm{mg} /$ day and this low intake of chili had no effect on incidence of gastric cancer. On the other hand the risks could be due to aflatoxin contamination not the capsaicin effect. Tsuchiya et al., ${ }^{34}$ compared the effect of pure capsaicin and red chili as mutagens and found capsaicin caused no mutagenesis. Since the red chilies were contaminated with aflatoxin they concluded that the mutagenesis cause was possibly due to the aflatoxin contamination and not the chili compounds.

Aflatoxin is a naturally occurring highly carcinogenic toxic sub-stance, produced in minute quantities. Chronic exposure to aflatoxins affects humans and livestock in a number of ways. It causes immunodeficiency and immunosuppression, stunting and kwashiorkor, which interferes with the metabolism of micronutrients in children, liver cancer, especially in people with hepatitis B or C and liver disease ${ }^{37}$ Dry peppers were reported in many countries to be subject to aflatoxin contamination. In Nigeria Makun found 50\% of tested samples had aflatoxin levels higher than the acceptable levels. In Pakistan Khan et al., ${ }^{6}$ found the level of aflatoxin in 70 samples collected from different farms ranged 6.62 to $148 \mu \mathrm{g} / \mathrm{kg} .{ }^{38}$

Pepper is a highly consumed crop in Eritrea. It is part of the daily diet of most Eritreans. Thus contamination with aflatoxin above the acceptable limit will have undesirable effect on the health of people. Aflatoxin contamination could be due to poor farming, harvesting and post harvest practices. Factors affecting aflatoxin contamination levels are moisture, temperature, packaging and storage. ${ }^{6}$ Drying vegetables under sun, selling in open, high humidity and temperature could be favorable for mycotoxins. In Eritrea levels of aflatoxin contamination is not reported. However, harvesting, drying, packing, storage, retailing practices indicate to possibility of high level contamination. Results of Interviewing 102 farmers regarding pepper drying methods showed that sun drying, shade drying and a mixture of them which indicates to possibility of contamination are the most common among pepper growers in Eritrea. ${ }^{6}$ In addition to that spraying water on dry pepper for increasing weight was observed to be a common practice among small retailers who sell in open markets of Asmara. Similarly storage facilities in small shops and whole sale stores are also inviting condition for contamination with the fungus. Thus it is important to determine the level of aflatoxin contamination at farm level, retail markets and whole sale stores for creating awareness and proper design of controlling strategies so that associated health risks avoided. Several methods were suggested to reduce aflatoxin contamination in chili at farm level and in marketing chain. Saleh et al., ${ }^{6}$ found sorting of discolored and viscera opened pods could reduce contamination level. Similarly, Saleh et al., ${ }^{6}$ found physical sorting regarding shape, size and color of to be effective in reducing aflatoxin contamination. Chili pods dried on concrete ground or in string were found to less contaminated compared to those dried on soil or Asphalt. Controlling moisture and temperature, packing, storage, etc., can reduce aflatoxin contamination in chilies and chilies products. ${ }^{6}$

\section{Conclusion}

In Eritrea pepper cultivation and use has long history, but no evidence of its use as medicinal plant. Medicinal uses and health benefits of pepper are globally well documented. However issues related to safety, efficacy, quality, and development and potential risks, especially those linked to aflatoxin contamination need to be researched. On the other hand farmers can contribute reducing in aflatoxin contamination at farm level by removing discolored fruits and improving drying method.

\section{Acknowledgements}

None.

\section{Conflict of interest}

Author declares that there is no conflict.

\section{References}

1. Kraft $\mathrm{KH}$, Brown $\mathrm{CH}$, Nabhan GP, et al. Multiple lines of evidence for the origin of domesticated chili pepper, Capsicum annuum, in Mexico. Proc Natl Acad Sci USA. 2014;111(17):6165-6170.

2. Andrews J. Pepper Trail: History and Recipes from around the world. USA: University of North Texas Press; 1999. 256p.

3. Bosland PW. Capsicums: Innovative Uses of an Ancient Crop. In: Janick J editor. Progress in new crops. USA: ASHS Press; 1996:479-487.

4. Moscone E, Scaldaferro MA, Grabiele M, et al. The evolution of chili peppers (Capsicum-Solanaceae): a cytogenetic perspective. Acta Horticulturae. 2007;745:137-170.

\section{FAO. FAOSTAT, Crops. FAO Statistics Division. 2018.}

6. Saleh B Khiar, Nyende AB, Kasili R, et al. Current Status and Future Opportunities of Pepper Production in Eritrea. ARPN Journal of Agricultural and Biological Science. 2013;8(9):655-672.

7. Saleh B Khiar, Remmy W Kasili, Mamati EG, et al. Genetic Diversity and Population Structure of Eritrean Pepper (Capsicum species) as Revealed by SSR Markers. Molecular Plant Breeding. 2016;7(11):1-16.

8. Saleh B Khiar. Production Status, Genetic Characterization of Eritrean Pepper (Capsicum spp.) and Evaluation of F1 Hybrids for Yield and Fruit Quality. A PhD thesis. Kenya: Jomo Kenyatta University of Agriculture and Technology; 2016. 218p. 
9. Paran I, Van Der Knaap E. Genetic and molecular regulation of fruit and plant domestication traits in tomato and pepper. Journal of Experimental Botany. 2007;58(14):3841-3852.

10. Djian-Caporalino. Theoretical and Applied Genetics. 2009;119(6):973989.

11. Senai W Andemariam. Legislative Regulation of Traditional Medicina Knowledge in Eritrea vis-à-vis Eritrea's Commitments under the Convention on Biological Diversity: Issues and Alternatives. Law Environment and Development Journal. 2010;6(2):1-37.

12. Macfarlane GJ, Ashraf EM, Bird H, et al. Complementary and alternative medicines report. UZK: Arthritis Researc; 2012.

13. Pawar SS, Bharude NV, Sonone SS, et al. Chilies as food, spice and medicine: A perspective. International Journal of Pharmacy and Biological Sciences. 2011;1(3):311-318.

14. Abdul Salam SGS. Biochemical Studies on Peppers as Specific Foodstuffs. Egypt: $C U$ thesis; 2015.

15. Howard LR, Talcott ST, Brenes CH, et al. Changes in Phytochemical and Antioxidant Activity of Selected Pepper Cultivars (Capsicum Species) As Influenced by Maturity. J Agric Food Chem. 2000;48(5):1713-1720.

16. Ganguly S, Praveen KP, Para PA. Medicinal Properties of Chilli Pepper in Human Diet. ARC Journal of Public Health and Community Medicine. 2017;2(1):6-7.

17. Fattori V, Hohmann MS, Rossaneis AC. Capsaicin: Current Understanding of Its Mechanisms and Therapy of Pain and Other PreClinical and Clinical Uses. Molecules. 2016;21(7):E844.

18. Rodriguez-Burruezo A, Kollmannsberger H, Prohens J. Comparative analysis of pungency and pungency active compounds in Chile peppers (Capsicum ssp.). Bull UASVM Horticulture. 2010;67(1):270-273.

19. Bosland PW, Walker SJ. Measuring Chile Pepper Heat. USA: College of Agricultural, Consumer and Environmental Sciences, New Mexico State University; 2010:1-2.

20. Bosland PW, Coon D, Reeves G. 'Trinidad Moruga Scorpion' Pepper is the World's Hottest Measured Chile Pepper at More Than Two Million Scoville Heat Units. Hortechnology. 2012;22(4):534-538.

21. Stewart C, Kang B, Liu K, et al. The Pun1 gene for pungency in pepper encodes a putative acyltransferase. The Plant Journal. 2005;42(5):675688 .

22. Votava EJ, Bosland PW. Novel Sources of Non-pungency in Capsicum species. Capsicum and Eggplant Newsletter. 2002;21:66-68.

23. Spice Sector Strategy Coordinating Committee Spice Sub-Sector STRATEGY for ETHIOPIA, ACP Agricultural Commodities Programme. International Trade Centre (ITC), Division of Country Programmes (DCP), Export Strategy; 2010.
24. Caterina MJ, Schumacher MA, Tominaga M, et al. The capsaicin receptor: a heat-activated ion channel in the pain pathway. Nature. 1997;389(6653):816-824.

25. Szallasi A. Vanilloid (Capsaicin) Receptors in Health and Disease. Am Journal Clinical Pathology. 2002;118:110-121.

26. Geppetti P, Trevisani M. Activation and sensitization of the vanilloid receptor: role in gastrointestinal inflammation and function. British Journal of Pharmacology. 2004;141(8):1313-1320.

27. Sun F, Xiong S, Zhu Z. Dietary Capsaicin Protects Cardiometabolic Organs from Dysfunction. Nutrients. 2016;8:174.

28. Omolo MA, Wong Z, Mergen AK. Antimicrobial Properties of Chili Peppers. Journal Infectious Diseases and Therapy. 2014;2:145.

29. Perucka I, Materska M. Antioxidant vitamin contents of Capsicum annum fruit extract as affected by processing and varietal effects. Acta Sci Pol Technol Aliment. 2007;6(4):67-74.

30. Mateos et al. Antioxidant Systems from Pepper (Capsicum annuum L.): Involvement in the Response to Temperature Changes in Ripe Fruits. Int J Mol Sci. 2013;14:9556-9580.

31. Materska M, Perucka I. Antioxidant Activity of the Main Phenolic Compounds Isolated from Hot Pepper Fruit (Capsicum annuum L.). J Agric Food Chem. 2005;53(5):1750-1756.

32. Hwang MK, Bode AM, Byun S, et al. Cocarcinogenic Effect of Capsaicin Involves Activation of EGFR Signaling but Not TRPV1. Cancer Research. 2010;70(17):6859-6869.

33. Asai T, Tsuchiya Y, Okano K, et al. Aflatoxin contamination of red chili pepper from Bolivia and Peru, countries with high gallbladder cancer incidence rates. Asian Pacific Journal of Cancer Prevention. 2012;13(10):5167-5170.

34. Tsuchiya Y, Terao M, Okano K, et al. Mutagenicity and Mutagens in the red chili pepper as gallbladder cancer risk factor in chilean women. Asian Pac J Cancer Prev. 2011;12(2):471-476.

35. Szllasi A, Blumberg PM. Vanilloid (Capsaicin) Receptors and Mechanisms. Pharmacological Reviews. 1999;51(2):159-212.

36. SCF. Opinion of the Scientific Committee on Food on Capsaicin. SCF/ CS/FLAV/FLAVOUR/8 ADD1 Final. Scientific Committee on Food, Health and Consumer Protection Directorate, European Commission, Brussels; 2002

37. Waliyar F, Ndjeunga J, Diarra B. Aflatoxin in Mali: A Review. USA: International Food Policy Institute; 2010

38. Rodrýguez Maza M, Garces Claver A, Park S, et al. A versatile PCR marker for pungency in Capsicum spp. Mol Breeding. 2012;30(2):889898. 